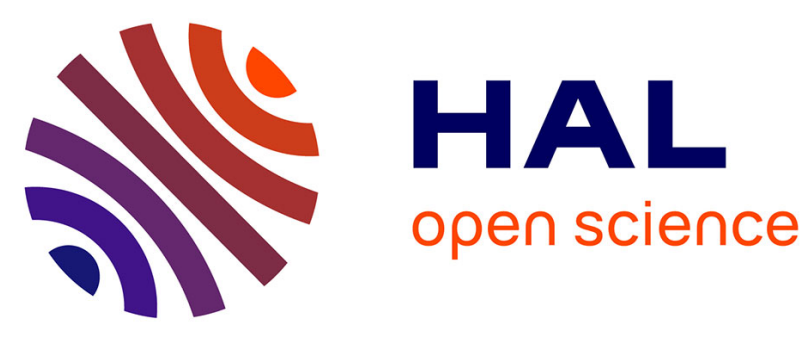

\title{
Smart Grids Simulation with MECSYCO
}

Julien Vaubourg, Yannick Presse, Benjamin Camus, Christine Bourjot, Laurent Ciarletta, Vincent Chevrier, Jean-Philippe Tavella, Hugo Morais, Boris Deneuville, Olivier Chilard

\section{- To cite this version:}

Julien Vaubourg, Yannick Presse, Benjamin Camus, Christine Bourjot, Laurent Ciarletta, et al.. Smart Grids Simulation with MECSYCO. PAAMS'15, Jun 2015, Salamanca, Spain. pp.4, 10.1007/978-3319-18944-4_37. hal-01171445

\section{HAL Id: hal-01171445 https://hal.inria.fr/hal-01171445}

Submitted on 3 Jul 2015

HAL is a multi-disciplinary open access archive for the deposit and dissemination of scientific research documents, whether they are published or not. The documents may come from teaching and research institutions in France or abroad, or from public or private research centers.
L'archive ouverte pluridisciplinaire HAL, est destinée au dépôt et à la diffusion de documents scientifiques de niveau recherche, publiés ou non, émanant des établissements d'enseignement et de recherche français ou étrangers, des laboratoires publics ou privés. 


\title{
Smart Grids Simulation with MECSYCO
}

\author{
Julien Vaubourg ${ }^{1,3} \quad$ Yannick Presse ${ }^{1,3} \quad$ Benjamin Camus ${ }^{2,3}$ \\ Christine Bourjot ${ }^{2,3} \quad$ Laurent Ciarletta ${ }^{1,3}$ \\ Vincent Chevrier ${ }^{2,3} \quad$ Jean-Philippe Tavella ${ }^{4}$ \\ Hugo Morais $^{4} \quad$ Boris Deneuville ${ }^{4} \quad$ Olivier Chilard $^{4}$
}

3rd June, 2015

1 Julien.Vaubourg; Yannick.Presse; Laurent.Ciarletta\}@inria.fr Inria, Villers-lès-Nancy, F-54600, France

${ }^{2}\{$ Benjamin.Camus; Christine.Bourjot; Vincent.Chevrier\}@loria.fr

3 Université de Lorraine, LORIA, UMR 7503, Vandœuvre-lès-Nancy, F54506, France / CNRS, LORIA, UMR 7503, Vandœuvre-lès-Nancy, F-54506, France

${ }^{4}$ Jean-Philippe.Tavella; Hugo.Morais; Boris Deneuville; Olivier Chilard\}@edf.fr

EDF - R\&D MIRE/R44 1, avenue du Général de Gaulle BP 408 F-92141 Clamart cedex 


\section{Introduction}

These demonstrations show the current results of the DEVS-based platform called MECSYCO (Multi-agent Environment for Complex SYstems CO-simulation), formerly named AA4MM (Agents \& Artifacts for Multi-Modeling [1]), in the context of smart grids simulation with different use cases based on real scenarios.

This work (described in 2 2 ) results of MS4SG (Multi-Simulation for SmartGrids), a joint project between LORIA-INRIA and EDF R\&D which aims at providing attractive technological solutions to test new distributed algorithms (e.g. advanced voltage management) or original operating mode (e.g. islanding) before their use in real prototypes and even in the real networks.

\section{Smart grid simulation}

The modeling and simulation of a smart grid system should integrate different domains of expertise (at least: power grid; communication; and information and decision systems). In MS4SG, each domain uses different tools; and, in the same domain, several different tools may have to cohabit. For example, the electricity domain uses executable Modelica 3 models exported from Dymola 4 or EMTPRV (ElectoMagnetic Transient Program, Restructured Version[5]) as modeling tools of power grid components; the telecommunication network domain may use NS-3 [6] or OMNeT++ 7] depending on the protocols requirements; and decision systems can be modeled with UML-oriented tools such as Enterprise Architect 8].

The central problem is then the multi-simulation that intends to simulate the whole as the coordinated simulation of several heterogeneous and interacting simulators. Handling heterogeneity and enabling the interaction between components can be envisaged at different levels such as the one of formalisms, of time management, of information representation, etc.; with the constraint of integrating co-simulation norms and standards.

The solution we adopted is based on a meta-modeling approach with multiagent concepts (Agents and Artifacts [9]) to describe a heterogeneous multimodel. These concepts are formalized with DEVS[10] (Discrete Event System Specification) operational specifications. The DEVS formalism ensures the integration of different formalisms with simulation algorithms. We chose as simulation algorithm the parallel conservative DEVS simulator based on the ChandyMisra algorithm [11] that enables a decentralized execution. We exploited its possibility by implementing the concepts either in $\mathrm{C}++$ or in Java.

The resulting middleware, MECSYCO, is able to integrate the different kinds of heterogeneity of the smart grid use cases and to simulate the whole in a decentralized way. 


\section{The Concept-Grid use case}

The demonstration is a use case, Concept-Grid, that combines electrical models and communication network models with a decisional system model. These three kinds of model correspond to the three main fields of smart grids. This use case was tested with a real life demonstrator stated at EDF Lab Les Renardières and named Concept-Grid. This demonstrator includes an MV/LV electrical grid with five real houses enabling measurements to compare with the simulation results.

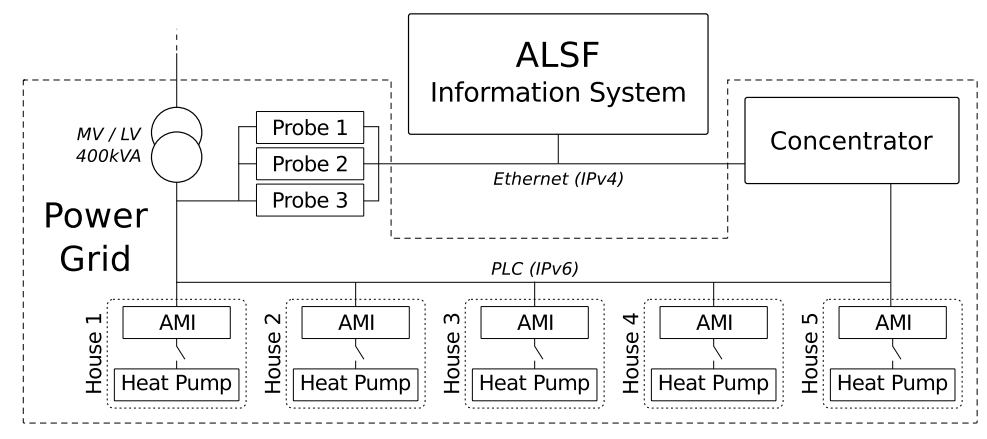

Figure 1: Overview of the Concept-Grid use case.

A general overview of the use case is described in Fig. 1. It corresponds to a load shedder with a cascado-cyclic algorithm and five consuming houses. Each house is equipped with a heat pump and an AMI (Advanced Metering Infrastructure also known as Linky) smart meter. The heat pumps are always enabled, except in a time slot determined by the ALSF (Advanced Load Shedding Function) decisional system. This last sends a message to meters to indicate their shedding time slot (specific to each house); the meters are responsible for enabling or disabling the heat pump during the simulation according to this information.

This use case involves different types of heterogeneity:

- multi-domain: ALSF corresponds to a decisional model, communications between equipments correspond to two communication network models (PLC and Ethernet) and power grid to electrical models;

- multi-simulator: communication models are simulated with NS-3, power grid components and AMI as FMU: simulated in an ad-hoc Java automaton;

- multi-formalism: FMUs are equation-based, NS-3 models are event-based;

\footnotetext{
${ }^{1}$ Each FMU (Functional Mock-up Unit) corresponds to a set of equations with its solver, exported from tools compliant with FMI (Functional Mock-up Interface), a standard [12] to handle the coupling of models described by differential, algebraic, and discrete equations.
} 


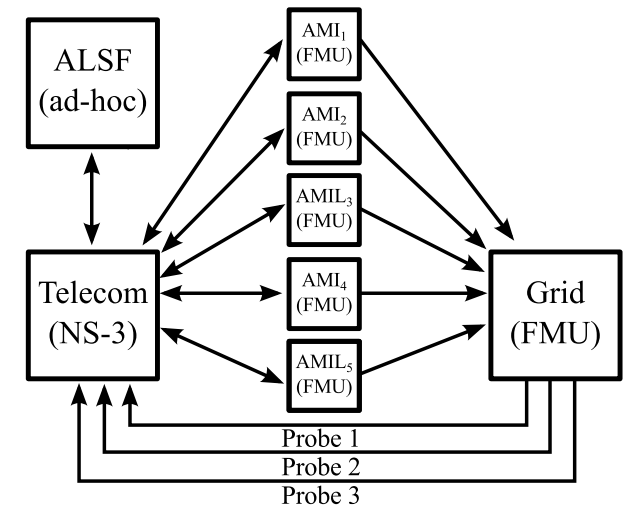

Figure 2: The Concept-Grid use case with the different simulators interactions.

- multi-language: FMU wrappers and decision system are in Java language, NS-3 is in $\mathrm{C}++$;

- multi-platform: FMUs are executed on Windows while NS-3 is on GNU/Linux.

Implementation involves several different existing simulators: the power grid (one FMU), the AMIs (one FMU for each), the communication network (NS-3) and the decision system (an automaton in Java). Each simulator is managed by an agent (namely m-agent) in charge of the interactions of its model with the other ones. Interactions are reified through artifacts. M-agents and artifacts are provided by the MECSYCO middleware. Wrappers of simulators are specific to the simulation software (we only developed one FMU-wrapper, not one for each simulator). Fig. 2 corresponds to the interactions between the simulators.

Demonstrations show the results provided by the simulation. In addition, they are completed by pedagogical proof of concepts focusing on each specific issue solved by MECSYCO.

\section{Conclusion}

The demonstrations show a use case based on smart grid real scenarios as an example of complex system. They demonstrate the ability of the MECSYCO simulation middleware to handle different kinds of heterogeneity in a homogeneous, multi-agent oriented point of view with a fully decentralized execution.

\section{Acknowledgement}

This work is partially funded by EDF R\&D through the strategic project MS4SG. 


\section{References}

[1] Siebert, J., Ciarletta, L., Chevrier, V.: Agents and artefacts for multiple models co-evolution: building complex system simulation as a set of interacting models. In: Proceedings of AAMAS '10. (2010) 509-516

[2] Vaubourg, J., Presse, Y., Camus, B., Bourjot, C., Ciarletta, L., Chevrier, V., Tavella, J.P., Morais, H.: Multi-agent multi-model simulation of smart grids in the ms4sg project. In: Proc. of PAAMS'15. (2015)

[3] Fritzson, P., Engelson, V.: Modelica - a unified object-oriented language for system modeling and simulation. In Jul, E., ed.: ECOOP'98. LNCS. (1998)

[4] Dynamic Modeling Laboratory (Dymola): http://www.3ds.com/productsservices/catia/capabilities/modelica-systems-simulation-info/dymola

[5] Mahseredjian, J., Dennetière, S., Dubé, L., Khodabakhchian, B., GérinLajoie, L.: On a new approach for the simulation of transients in power systems. Electric Power Systems Research 77(11) (2007)

[6] Henderson, T.R., Roy, S., Floyd, S., Riley, G.F.: NS-3 project goals. In: Proceeding of WNS2 '06, ACM (2006) 13

[7] Varga, A., Hornig, R.: An overview of the OMNeT++ simulation environment. In: Proceedings of ICST. (2008) 60

[8] Enterprise Architect: http://www.sparxsystems.com.au/products/ea/index.html

[9] Ricci, A., Viroli, M., Omicini, A.: Give agents their artifacts: the A\&A approach for engineering working environments in MAS. In: Proc. AAMAS '07, ACM (2007)

[10] Zeigler, B., Praehofer, H., Kim, T.: Theory of Modeling and Simulation: Integrating Discrete Event and Continuous Complex Dynamic Systems. Academic Press (2000)

[11] Chandy, K.M., Misra, J.: Distributed simulation: A case study in design and verification of distributed programs. IEEE Trans. Software Engineering, (1979)

[12] Blochwitz, T., Otter, M., Arnold, M., et al.: The functional mockup interface for tool independent exchange of simulation models. In: 8th International Modelica Conference. (2011) 20-22 